\title{
Adjuvant liver perfusion in colorectal cancer: initial results of a clinical trial
}

\author{
I TAYLOR，P BROOMAN，J T ROWLING
}

British Medical fournal, 1977, 2, 1320-1322

\section{Summary}

Fifty consecutive patients with colorectal cancer but no evidence of secondary deposits in the liver were included in an ongoing controlled clinical trial of adjuvant liver perfusion aimed at reducing the incidence of hepatic metastases. All patients had their primary tumour resected in the standard way. Twenty-six of the patients served as controls, and 24 received fluorouracil, $1 \mathrm{~g}$ daily, as a continuous infusion into the portal venous system during the first seven days after operation. The patients were matched for age, sex, and site and stage of the disease.

The immediate postoperative mortality and morbidity did not differ significantly between the two groups. During the follow-up period (mean duration 15.5 months), however, six deaths occurred in the control group and only one in the perfusion group., At necropsy four of the controls had multiple liver metastases. Two of the surviving controls developed evidence of liver metastases, and two had a local recurrence. No patient in the perfusion group developed evidence of hepatic metastases.

These initial results suggest that adjuvant portal venous perfusion with fluorouracil may reduce the incidence of liver metastases in colorectal cancer.

\section{Introduction}

There has been a depressing stability in the five-year survival rate for colorectal cancer over the past $20-30$ years $^{1}$ despite advances in surgical techniques. It remains the second most common cancer throughout the Western world, accounting for some 15000 deaths a year in England and Wales. Attempts to improve survival rates by using systemic chemotherapy (usually with 5-fluorouracil) as an adjuvant to surgery have been difficult to assess owing to toxic side effects. A report ${ }^{2}$ on treatment with fluorouracil five to six weeks after surgery suggested an improvement in the five-year survival rate of patients with Dukes's category $\mathrm{C}$ disease, but other reports ${ }^{3}$ have been less convincing, even when treatment was supplemented with intermittent courses of oral fluorouracil. ${ }^{4}$

The failure of surgery in this condition usually is due to its inability to control or prevent metastases, particularly in the liver. At laparotomy up to $25 \%$ of patients have macroscopic evidence of secondary deposits in the liver. ${ }^{5}$ Malignant cells may be disseminated by embolism into the portal venous system at operation, and cancer cells have been found in venous blood draining tumours of the large bowel. ${ }^{6}$ Those malignant cells that survive probably remain dormant within the liver until they start to proliferate, forming micrometastases that penetrate into the interstitial space. ${ }^{7}$ As they increase in size they derive a circulation from the hepatic artery, but in the early stages they retain their blood supply from the portal vein.

University Department of Surgery, Liverpool L69 3BX

I TAYLOR, MD, FRCs, senior lecturer and consultant surgeon

Royal Hospital, Sheffield S1 3SR

P BROOMAN, FRCS, surgical registrar

J T ROWLING, MD, FRCs, consultant surgèon
Our aim was to determine whether the incidence of liver metastases could be diminished and the survival rate in colorectal cancer improved by infusing fluorouracil into a portal vein. The study is continuing and we report here the initial results.

\section{Patients and methods}

Fifty consecutive patients with primary colorectal cancer were studied, none of whom had macroscopic evidence of secondary deposits in the liver. All had the primary tumour resected in the standard manner. Twenty-four of the patients (13 women and 11 men) were allocated at random to receive liver perfusion with fluorouracil through the portal vein, and the remaining 26 (16 women and 10 men) received no treatment other than the primary resection. Measurements of liver function-namely, serum bilirubin, serum alkaline phosphatase, serum aspartate aminotransferase (SGOT), and serum lactic dehydrogenase (LDH) concentrations-and a full haematological assessment were performed before and after operation. All patients had similar bowel preparation before operation, and most also had ${ }^{99 \mathrm{~m}} \mathrm{Tc}$-sulphur colloid liver scanning.

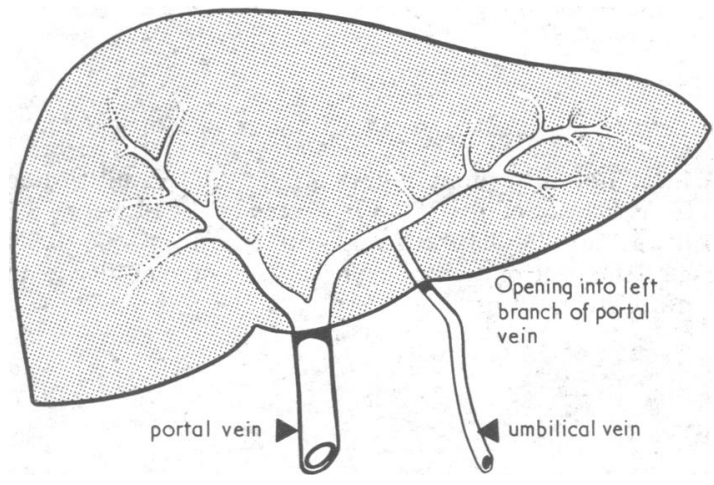

FIG 1-Diagram showing entrance of "obliterated" umbilical vein into left branch of portal vein.

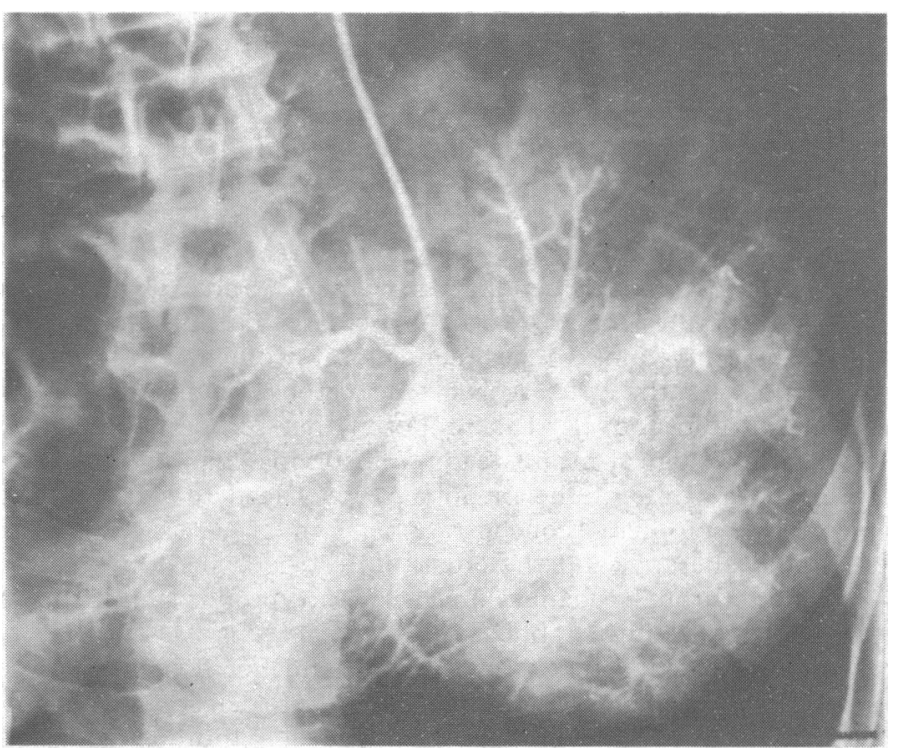

FIG 2-Portal venogram obtained by injecting contrast medium into umbilical vein catheter. Note equal distribution to the two main lobes of liver. 
Access to the portal vein was achieved by dilating and cannulating the "obliterated" umbilical vein (fig 1). " 1 "A No 72 Surgimed catheter with four side holes was used. No great difficulty was encountered with the technique. In two patients a cholecystectomy had been performed and the falciform ligament divided; hence in these patients the umbilical vein could not be cannulated, and they were not included in the trial. Continuous infusion starting as soon as possible after resection was carried out for the first seven days. $1 \mathrm{~g}$ fluorouracil, in $5^{\prime \prime}$ "dextrose, was given per day, and heparin (5000 U/day) was included to discourage portal vein thrombosis.

To ensure that perfusion of the two main lobes was equal, contrast medium was injected into the catheter under the image intensifier (fig 2). If necessary the catheter could be manipulated under the image intensifier until the right and left portal veins were equally perfused. Penicillin and gentamicin were given to both groups for seven days. The operative specimens were examined and the growths classified according to Dukes's ${ }^{11}$ categorisation $(\mathrm{A}, \mathrm{B}, \mathrm{C})$ of the extent of spread.

During the postoperative period blood counts and liver function tests were performed on alternate days. Follow-up ranged from 9 to 21 (mean 15.5) months. All patients were assessed regularly in the outpatient department, where the blood tests were repeated, and ${ }^{99 \mathrm{~m}} \mathrm{Tc}-$ sulphur colloid liver scanning was performed after six and 12 months and then once a year.

\section{Results}

The two groups were well matched for age, sex, and site and stage of the disease according to Dukes's classification (table I).

TABLE I-Details of the two groups of patients including extent of spread of the disease (assessed according to Dukes's A B C classification)

\begin{tabular}{|c|c|c|c|c|c|c|c|c|}
\hline & \multirow{2}{*}{$\begin{array}{l}\text { Mean age } \\
\text { (years) } \\
1 \text { SE of } \\
\text { mean }\end{array}$} & \multicolumn{3}{|c|}{$\begin{array}{l}\text { No with } \\
\text { colonic } \\
\text { disease }\end{array}$} & \multicolumn{3}{|c|}{$\begin{array}{l}\text { No with } \\
\text { rectal } \\
\text { disease }\end{array}$} & \multirow{2}{*}{$\begin{array}{c}\text { Mean } \\
\text { follow-up } \\
\text { period } \\
\text { (months) } \\
\therefore \text { ISE of } \\
\text { mean }\end{array}$} \\
\hline & & A & B & C & A & B & C & \\
\hline $\begin{array}{l}\text { Control group }(n-26) \\
\text { Perfusion group }(n \quad 24)\end{array}$ & $\begin{array}{ll}65 \cdot 3 & 2 \cdot 5 \\
65 \cdot 0 & 1 \cdot 8\end{array}$ & $\begin{array}{l}2 \\
3\end{array}$ & $\begin{array}{l}5 \\
6\end{array}$ & 4 & $\begin{array}{l}3 \\
2\end{array}$ & $\begin{array}{l}5 \\
3\end{array}$ & $\begin{array}{l}7 \\
7\end{array}$ & $\begin{array}{ll}15 \cdot 5 & 0.7 \\
15.4 & 0.7\end{array}$ \\
\hline
\end{tabular}

TABLE II-Incidence of postoperative morbidity in the two groups

\begin{tabular}{l|c|c}
\hline & $\begin{array}{c}\text { No of cases in control } \\
\text { group }\end{array}$ & $\begin{array}{c}\text { No of cases in perfusion } \\
\text { group }\end{array}$ \\
\hline $\begin{array}{l}\text { Wound infection } \\
\text { Fistulae }\end{array}$ & 9 & 5 \\
Alopecia & 3 & 2 \\
Oral ulceration & & 1 \\
Transient leucopenia & & 1 \\
Transient thrombocytopenia & & 2 \\
\hline
\end{tabular}

Postoperative morbidity-Nine patients in the control group $\left(34 \cdot 6^{\circ}{ }_{10}\right)$ and five in the perfusion group $\left(20 \cdot 8^{\circ}{ }_{0}\right)$ developed a wound infection (table II). The chief organisms were Escherichia coli and bacteroides. Faecal fistulae occurred in two patients in the perfusion group and three of the controls-a fistula being assumed if any faecal or faeculent material was discharged from the peritoneal drain. Gastrografin enemas were not performed. One patient developed partial alopecia and another transient oral ulceration during perfusion. There was no significant difference in length of hospital stay between the two groups, the mean stay being $14 \cdot 2$ (range $7-28$ ) days in the control group and 12.9 (range 9-23) days in the perfusion group.

Postoperative mortality-In the immediate postoperative period three deaths occurred in the control group and two in the perfusion group. Necropsy was carried out in all cases, and there was no evidence that the perfusion had contributed in any way to death. Of the three controls who died, one (aged 69) was found to have bronchopneumonia and a fistula, one (75) myocardial ischaemia, and one (67) myocardial infarction. The two deaths in the perfusion group resulted from a massive pulmonary embolus in one patient (aged 73) and bronchopneumonia in the other (76).

Laboratory Investigations-Both groups had disturbed liver function values during the first 10 days after operation (fig 3). There was no significant difference in serum bilirubin, alkaline phosphatase, or LDH between the two groups, but SGOT was significantly increased in the perfusion group between the second and the sixth postoperative

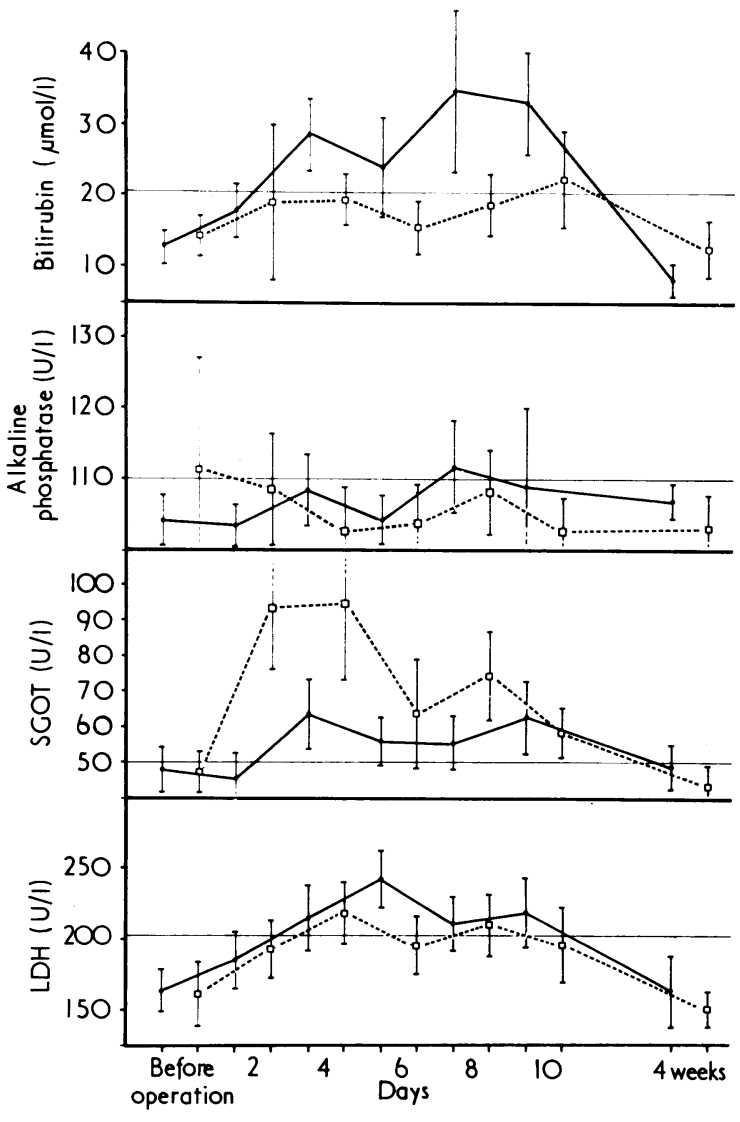

FIG 3-Mean liver function values ( $+1 \mathrm{SE}$ of mean) in control and perfusion groups (solid and dotted lines respectively) in postoperative period and at four weeks. Conversion: SI to traditional units-Serum bilirubin: $1 \mu \mathrm{mol} / 1 \approx 0.05 \mathrm{mg} / 100 \mathrm{ml}$.

days $(\mathbf{P}<0.05)$. It then began to fall and at four weeks was within normal limits. Three patients in the perfusion group had a transient leucopenia $\left(2.3,3.2\right.$, and $1.5 \times 10^{9} / 1 ; 2300,3200$, and $\left.1500 / \mathrm{mm}^{3}\right)$ and two transient thrombocytopenia (55 and $40 \times 10^{9} / 1$ ). All values returned to normal on completion of perfusion. It was not necessary to stop the perfusion in any patient.

Follow-up-The mean periods of follow-up were 15.5 months in the control group and 15.4 months in the perfusion group. Altogether six deaths occurred during this period in the control group. In four cases multiple liver metastases were found at necropsy, and in the other two carcinomatosis peritonei. The one death in the perfusion group was due to extensive local recurrence after an anterior resection for carcinoma of the rectum. Another two patients in the control group had suggestive evidence of liver metastases on the liver scan. The scans were reported on by a radiologist who did not know to which group the patient belonged. Thus six patients in the control group developed evidence of liver metastases but none in the perfusion group (table III). Two patients in the control group and one in the perfusion group developed local pelvic recurrence.

TABLE III-Results of follow-up assessment of the two groups (Dukes's classification given in parentheses)

\begin{tabular}{l|c|c}
\hline & $\begin{array}{c}\text { No of cases in control } \\
\text { group }\end{array}$ & $\begin{array}{c}\text { No of cases in perfusion } \\
\text { group }\end{array}$ \\
\hline Death & 6 \\
$\begin{array}{l}\text { Liver metastases found at } \\
\text { necropsy }\end{array}$ & $\begin{array}{l}\text { (B, B, B, C, C) } \\
\begin{array}{l}\text { Abnormal liver scan } \\
\text { Local recurrence }\end{array}\end{array}$ & $1(\mathrm{C})$ \\
\hline
\end{tabular}

\section{Discussion}

Over the past few years attempts have been made to improve the survival rate for colorectal cancer by means of adjuvant 
chemotherapy. Fluorouracil is the most effective agent now available for the systemic treatment of advanced and metastatic disease. Its value as adjuvant treatment at the time of initial surgery, however, is controversial. Li and Ross ${ }^{2}$ reported encouraging results with fluorouracil given four to six weeks after surgery. Rousselot et al $^{12}$ used a combination of intraluminal and intravenous fluorouracil in patients with Dukes's category C disease with some improvement. Other reports have shown little or no benefit when side effects are taken into account, although the combination of fluorouracil and BCG may be more effective. ${ }^{13}$

The liver is a favourable site for colorectal metastases. Up to half of the tumours give rise to liver metastases, and once they become established the outlook is bleak. Bengmark and Hafström $^{5}$ reported a survival time of five to seven months, Jaffe et al a mean of 146 days, ${ }^{14}$ and Pestana et al a mean of nine months. ${ }^{15}$ The survival rate appears to be the same in patients with hepatic metastases whether a palliative resection of the colon or some form of bypass procedure is carried out. ${ }^{5}$ This suggests that hepatic metastases are a chief cause of death in these patients.

Our study was designed to assess whether adjuvant liver perfusion with fluorouracil would prevent the development of secondary deposits in the liver after resection for colorectal cancer. Malignant cells are thought to enter the portal circulation either spontaneously or during surgery. Tumour cells have been recovered from the blood of major mesenteric venous channels in up to $32 \%$ of cases of colorectal cancer, ${ }^{6}$ including Dukes's category A. Though most of these cells perish, some remain to form a micrometastasis. ${ }^{7}$ Nitrogen mustard given when these cells are inoculated into rats reduces the number of "takes" of the malignant emboli, ${ }^{16}$ and on this theoretical basis fluorouracil is given as an adjuvant liver perfusion. Cell growth kinetics suggest that cell-cycle-specific chemotherapeutic agents should be more effective against small numbers of tumour cells than against bulky tumours that grow slowly. ${ }^{17}$ Thus fluorouracil given directly into the portal circulation in high concentrations is more likely to be effective in destroying "tumour emboli." Heparin is also given, chiefly to discourage portal vein thrombosis but also to prevent a fibrin clot developing around the tumour cells. ${ }^{7}$
Our initial results have been encouraging. The postoperative morbidity and mortality were no worse than in the control group. The liver can presumably take the brunt of the high dosage and limits the untoward systemic side effects that would otherwise occur with smaller doses given intravenously. The patients have been carefully followed up for a mean of 15.5 months. Six deaths in the control group due to recurrent disease have occurred and only one in the perfusion group. There was histological evidence of liver metastases in four patients and highly suggestive evidence (on liver scan) in a further two patients in the control group, but no suggestion of liver metastases in any patient in the perfusion group. The numbers are so far too small and the periods of follow-up too short, however, for accurate statistical analysis.

Possibly techniques designed to prevent the development of liver metastases could be combined with other methods designed to limit local recurrence, such as immunotherapy ${ }^{13}$ or local radiotherapy, in an attempt to improve the overall prognosis for patients with colorectal cancer.

\section{References}

1 Slaney, G, Modern Trends in Surgery, vol 3. London, Butterworths, 1971. ${ }^{2} \mathrm{Li}, \mathrm{M} \mathrm{C}$, and Ross, S T, Fournal of the American Medical Association, 1976, 235, 2825.

${ }^{3}$ Higgins, G A, et al, Archives of Surgery, 1971, 102, 339.

${ }^{4}$ Lawrence, W, Annals of Surgery, 1975, 181, 616.

5 Bengmark, S, and Hafström, L, Cancer (Philadelphia), 1969, 23, 198.

${ }^{6}$ Fisher, E R, and Turnbull, R B, Surgery, Gynecology and Obstetrics, $1955,100,102$.

: Hilgard, D, et al, European fournal of Cancer, 1972, 8, 347.

${ }^{8}$ Kessler, R E, and Zimmon, D S, Surgery, Gynecology and Obstetrics, 1967, 124, 594.

${ }^{9}$ Lavoire, P, Legare, A, and Vialetta, A, American fournal of Surgery, 1967, 114,822 .

${ }^{10}$ Man, B, Kraus, L, and Pikielny, S, Vascular Surgery, 1974, 8, 193.

11 Dukes, C E, fournal of Pathology and Bacteriology, 1940, 50, 527.

12 Rousselot, L M, et al, Diseases of the Colon and Rectum, 1972, 15, 169.

13 Mavligit, G M, et al, Lancet, 1976, 1, 871.

$14 \mathrm{Jaffe}, \mathrm{B}$ M, et al, Surgery, Gynecology and Obstetrics, 1968, 127, 1.

${ }_{15}$ Pestana, C, et al, American fournal of Surgery, 1964, 108, 826.

16 Morale, G F, et al, Annals of Surgery, 1957, 146, 588.

17 Schabel, F M, Cancer (Philadelphia), 1975, 35, 15.

\title{
Plasma fenfluramine levels, weight loss, and side effects
}

\author{
J A INNES, M L WATSON, M J FORD, J F MUNRO, MARGARET E STODDART, D B CAMPBELL
}

British Medical fournal, 1977, 2, 1322-1325

\section{Summary}

Fifty women with refractory obesity received fenfluramine for 20 weeks. Every two weeks details of weight change, drug dose, degree of anorexia, and any side effects were recorded and plasma was obtained for fenfluramine and norfenfluramine measurements. Of the 41 patients available for final analysis 26 achieved a maxi-

Eastern General Hospital, Edinburgh

J A INNES, MRCP, registrar

$M$ L WATSON, MRCP, senior house officer

$M$ J FORD, MRCP, medical registrar

J F MUNRO, FRCPED, consultant physician

MARGARET E STODDART, SRD, dietitian

Servier Research Institute, Greenford, Middlesex

D B CAMPBELL, BSC, MRIC, research director mum plateau dose of $160 \mathrm{mg} /$ day. Plasma fenfluramine concentrations did not correlate with the degree of anorexia or with the incidence of side effects other than the severity of dream disturbance. There was a highly significant relation between weight loss and plasma fenfluramine and norfenfluramine concentrations and also between weight loss and the presence of sustained anorexia. Women who achieved mean plateau concentrations over $200 \mathrm{ng} / \mathrm{ml}$ lost a mean of $8.8 \mathrm{~kg}$ while those with concentrations less than $100 \mathrm{ng} / \mathrm{ml}$ lost a mean of only $2 \cdot 1 \mathrm{~kg}$.

When fenfluramine is prescribed in refractory obesity the dose should be increased stepwise until either satisfactory weight loss is achieved or troublesome side effects appear.

\section{Introduction}

Fenfluramine is an effective anti-obesity agent, but its modes of action are controversial, and clinical response to treatment varies. 